\title{
Live birth after transfer of vitrified embryos from superovulated goats
}

\author{
Marlon B. Ocampo ${ }^{1,3}$, Juliana Q. Silvestre ${ }^{2}$,Virgilio D. Viernes ${ }^{3}$ and Lerma C. Ocampo ${ }^{1}$ \\ ${ }^{1}$ Reproductive Biotechnology Unit, Philippine Carabao Center, Science City of Muñoz, Nueva Ecija, Philippines \\ ${ }^{2}$ College of Veterinary Medicine, DMMMSU, Bacnotan, La Union; ${ }^{3}$ College of Veterinary Science and Medicine, \\ Central Luzon State University, Science City of Muñoz, Nueva Ecija, Philippines
}

\begin{tabular}{|l|l|}
\hline $\begin{array}{l}\text { Article history } \\
\text { Received: 25 Jan, 2016 } \\
\text { Revised: 15 Mar, 2016 }\end{array}$ & $\begin{array}{l}\text { Abstract } \\
\text { In this study, the viability of vitrified goat embryos recovered from superovulated non- } \\
\text { descript Philippine goats were evaluated post-warming by transferring to surrogate } \\
\text { does. Of 17 does treated for superovulation, 3 did not respond and 14 responded with a } \\
13.07 \text { mean ovulation rate. An average of 9.7 embryos per doe was collected at } \\
\text { different developmental stages. Using a container-less minimum drop size (MDS) } \\
\text { method of vitrification, 50 and } 64 \text { embryos were exposed to vitrification solution 1 } \\
\text { (VS1) containing 10\% ethylene glycol in basic medium (BM) consisting of Hepes } \\
\text { buffered TCM-199 medium + 20\% estrus-doe serum solution for 3 min and 10 min, } \\
\text { respectively. Immediately thereafter, the embryos were transferred to 40\% EG + } 1 \mathrm{M} \\
\text { sucrose in BM for 45 Sec before recovering and dropping directly into LN } \mathrm{N}_{2 .} \text { After 3 } \\
\text { months of storage, the embryos were warmed in 2 ml of 0.3 M sucrose in BM for 5 } \\
\text { min and washed twice before transferring into culture medium. Morphologically } \\
\text { normal embryos were then transferred surgically to 6 recipients. Seven kids were born } \\
\text { after a normal gestation period with birthweights ranging from 0.78-2.5 kg. The } \\
\text { results highlight the usefulness of the MDS method of vitrification using an ethylene } \\
\text { glycol based solution in the cryopreservation of goat embryos. That, continuous } \\
\text { research effort should be made for optimizing cryopreservation protocols for } \\
\text { conservation of animal genetic resources. } \\
\text { Keywords: Embryo transfer; live birth; superovulation; vitrification }\end{array}$ \\
\hline
\end{tabular}

To cite this article: Ocampo MB, JQ Silvestre, VD Viernes and LC Ocampo, 2016. Live birth after transfer of vitrified embryos from superovulated goats. Res. Opin. Anim. Vet. Sci., 6(2): 47-52.

\section{Introduction}

At present, interest has focused on vitrification as a rapid and efficient method for cryopreservation of mammalian embryos. The first successful vitrification of embryos was achieved with 8-cell mouse embryos using dimethyl sulfoxide (DMSO), acetamide, propylene glycol and polyethylene glycol as cryoprotectants, in which the embryos were exposed to vitrification solution at low temperature $\left(4^{\circ} \mathrm{C}\right)$ after stepwise equilibration to avoid its toxicity (Rall and Fahy, 1985). However, applying the same method to blastocyst stage embryos resulted in a lower survival rate (Hsu et al., 1986; Matsumoto et al., 1987). Besides, manipulating the embryos under a microscope at low temperature is not practical and the completion of the procedure before rapid cooling requires 25-40 min. Thus, succeeding efforts were directed at the

\footnotetext{
*Corresponding author: Marlon B. Ocampo, Reproductive Biotechnology Unit, Philippine Carabao Center, Science City of Muñoz, Nueva Ecija, Philippines; E-mail: ocampomarlon29@yahoo.com; Tel. No: 09098868938
} 
improvement of the vitrification procedure for embryo cryopreservation using the electron microscope grids (Martino et al., 1996), open pulled straws (Vajta et al., 1998), cryoloop (Lane et al., 1999a), cryotop (Kuwayama and Kato, 2000), microdrop method ( Kim et al., 2007; Ocampo et al., 2014), gel loading tip (Tominaga and Hamada, 2001) and a paper container (Kim et al., 2012) with the ultimate aim of preventing injury from intracellular ice formation. One remarkable improvement was the use of a simplified method using a vitrification solution based on ethylene glycol (Kasai et al., 1990; Yushiati and Holtz, 1990; Miyake et al., 1993; Zhu et al., 1993; Guignot et al., 2006) that allow rapid permeation of the cell within 2 min of treatment at $20^{\circ} \mathrm{C}$ before directly plunging the sample into liquid nitrogen. This method has also been proven effective for rabbit morula (Kasai et al., 1992).

In goat, the first successful embryo freezing and transfer was accomplished in using expanded blastocyst embryos (Bilton and Moore, 1976), followed by efforts in improving the method using ethylene glycol or glycerol (Le Gal et al., 1993; Rodriguez-Dorta et al., 2007). In this study, we examined the developmental competence to term of goat embryos derived from superovulation of non-descript Philippine goat using an ethylene glycol-based vitrification solution in a container-less vitrification procedure. Birth of live offsprings was used as the ultimate proof of the viability of embryos post vitrification and warming by transferring to recipients.

\section{Materials and Methods}

All media and chemicals were purchased from Sigma Aldrich Co., St. Louis, MO, USA, unless specifically indicated. Estrous-doe serum (EDS) was collected from the herd of Small Ruminant CentreCentral Luzon State University, Science City of Munoz, Nueva Ecija, Philippines by clotting the blood for $24 \mathrm{~h}$, then heat inactivated at $50^{\circ} \mathrm{C}$ for $30 \mathrm{~min}$, filtered $(0.22$ $\mu \mathrm{m})$ sterilized by filtration and stored in $1 \mathrm{ml}$ aliquots at $-20^{\circ} \mathrm{C}$ until use. The same pool of serum was used throughout the study.

\section{Superovulation treatment}

The study was carried out between September to December, during the breeding season using 17 normal cycling does (1-3 yrs old). Superovulation was induced by using follicle stimulating hormone (FSH: Antrin, Denka Seiyaku Co., Japan), given for 4 days at a decreasing dose starting from the $16^{\text {th }}$ day of the cycle for a total of $21 \mathrm{mg}$ through intramuscular route. Oestrus was induced by two injections of $12 \mathrm{mg}$ and 6 mg prostaglandin $\mathrm{F} \alpha\left(\mathrm{PGF}_{2} \alpha\right.$ : Panacelan $\mathrm{F}$, Daiichi Seiyaku Co., Japan) 48 and $60 \mathrm{~h}$ after the first injection of gonadotropins. To facilitate a uniform ovulation time, a 1000 IU of human chorionic gonadotropin (hCG: Puberogen, SankyoZoki Co., Japan) was injected intravenously at the onset of oestrus followed by two natural mating at about $12 \mathrm{~h}$ interval.

\section{Preparation of does for embryo recoveries and transfers}

Embryo recovery was performed at day 6 post mating under general anaesthesia. The does were starved for at least $24 \mathrm{~h}$ before being anesthesized with 1-2 ml anesthetic (Ilium Xylazil-20, Troy Lab., Australia) given intravenously. The midventral portion distal to the umbilicus was cleaned and disinfected before a 3 inch midline incision was made along the linea alba. The ovaries and the uterus were exteriorized and the ovarian response was recorded based on the number of corpus luteum (CL) present. The uterine horn was punctured at its base in order to introduce a Foley catheter (no,8), the balloon of which was inflated until it totally blocked the uterine lumen. A catheter (Argil medicut of $1.69 \mathrm{~mm}$ diameter) was introduced at the uterotubal junction to facilitate the injection of 50 $\mathrm{ml}$ phosphate buffered saline (PBS) enriched with $10 \%$ EDS and collected through the Foley catheter inserted at the base of the uterine horn. Each horn was flushed separately. Thereafter, the uterus was returned inside the abdominal cavity and the peritoneum and abdominal musculature was closed by using an absorbable cat gut. The skin incision was closed with a size 0 surgical silk.

The recipient does were prepared for embryo transfer on the $6^{\text {th }}$ day post natural oestrus. The embryos (3-4 embryos/doe) were deposited in the uterine horn ipsilateral to the ovary showing at least one functional CL by puncturing the horn with an 18 gauge needle and using it as a guide, the micropipette with the embryos was inserted in the hole and the embryos were deposited. The possible effect of season on the success rate of embryo transfer was not considered and transfers were conducted only whenever there were recipient(s) in oestrus (day 0 - onset of oestrus as manifested by the presence of mucus discharge and reddening/pinkish appearance of the cervix upon examination).

Care and management of all experimental animals were done through complete confinement method with provisions for adequate supply of concentrate feeds (200 g/head/day) and forage given twice daily. Ureamolasses mineral block was provided and water as the ad libitum basis. Pregnancies on recipients were determined by examining the onset of oestrus for two oestrous cycles. Does that did not exhibit signs of oestrus were assumed pregnant and allowed to progress to term. Confirmation of pregnancies was carried out between 60-90 days after transfer. The ultrasound technique (Noveko 5.0 MHz) adopted was the B-mode or real-time transabdominal ultrasonography. Prior to 
examination, the right side of the abdomen just in front of the mammary gland was shaved to remove the hair that may interfere with the data received by the ultrasound probe. Then, a Trans-Gel (ultrasound transmission gel- a water based contact medium for ultrasound transmission) was applied to ensure a clear projection of information to and from the probe.

\section{Embryo evaluation, vitrification and warming}

Recovered structures (unfertilized ova and embryos) were evaluated based on the stage of development and quality using morphological criteria. They were classified as unfertilized ova (no cleavage), degenerate embryos (embryos at 8- cell or earlier stage) or as transferable embryos grade 1,2 or 3 (morphologically intact compact morula, early blastocyst or expanded blastocytst). Grade 1 embryos were morphologically intact and had an even granulation and cell distribution, Grade 2 embryos with small deviations such as some extruded blastomeres or slightly asymmetrical in shape, while Grade 3 embryos with partial degeneration or other irregularities, including extruded blastomeres or vesicles, a loosened structure with numerous free blastomeres (Lindner and Wright, 1983; Nuti et al., 1987).

After grading, the embryos were maintained in basic medium (BM) consisting of TCM-199 medium + $20 \% \mathrm{EDS}$ at $39^{\circ} \mathrm{C}$ in an incubator with $5 \% \mathrm{CO}_{2}$ in air. Grade 1 and 2 embryos were then equilibrated for $3 \mathrm{~min}$ or $10 \mathrm{~min}$ in vitrification solution 1 (VS1) containing $10 \%$ ethylene glycol (EG) in BM, transferred to vitrification solution 2 (VS2) containing 40\% EG + $1 \mathrm{M}$ sucrose in $\mathrm{BM}$ for $45 \mathrm{Sec}$ before recovering and dropping directly into liquid nitrogen $\left(\mathrm{LN}_{2}\right)$. The embryo suspension were vitrified into pellet form, collected, placed into cryotubes and stored in a $\mathrm{LN}_{2}$ tank. After at least 3 months of storage, the embryo pellet(s) were warmed in $2 \mathrm{ml}$ of $0.3 \mathrm{M}$ sucrose in $\mathrm{BM}$ for $5 \mathrm{~min}$ maintained at $37^{\circ} \mathrm{C}$ on a warmed plate, transferred twice into washing medium to remove the residual sucrose and permit blastomere rehydration. After $10 \mathrm{~min}$, the embryos were evaluated morphologically and assigned for culture and/or transfer.

Warmed embryos assigned for culture were placed in $100 \mu \mathrm{l}$ droplets of BM overlaid with mineral oil in 10 x $35 \mathrm{~mm}$ petri dishes (Falcon 3001, Becton-Dickinson Labware, Lincoln Park, NJ, USA) and cultured at $39^{\circ} \mathrm{C}$ in a humidified atmosphere of $5 \% \mathrm{CO}_{2}$ in air for $48 \mathrm{~h}$. The embryos were examined based on their ability to expand and/or hatched. Embryos observed at expanded, hatching and/or hatched stage were considered to have survived the vitrification/warming procedure.

\section{Statistical analysis}

Data on vitrification and survival of embryos post warming were examined by Chi-Square test.

\section{Results}

Of 17 does treated for superovulation, 3 did not respond as evidenced by the absence of CL upon exposure of the ovaries through midventral laparotomy. The mean ovulation rate per doe was 13.07 with a total of 183 CL (range of 12-14 CL's). Recovered structures consisted of 3 unfertilized oocytes and 136 (4 cell to blastocyst stage) embryos from 14 does representing around $76.0 \%$ recovery rate with 9.7 embryos/doe (Table 1).

Of 136 embryos recovered, 6 morula stage embryos were transferred fresh to 2 recipients, 33 embryos (Grade 2) were cultured in vitro without vitrification (Control) and 97 embryos were vitrified. Of vitrified embryos, 31 and 66 embryos were in early (4-16 cell) and late (morula to blastocyst) stage, respectively. Ten early and 30 late stage embryos were exposed to VS1 for $3 \mathrm{~min}$ and 16 early- and 36 latestage embryos were exposed to VS1 for $10 \mathrm{~min}$. The survival rate of early stage embryos pre-equilibrated for $10 \mathrm{~min}$, was significantly higher than when exposed for 3 min. Similarly, the survival rate of late stage embryos pre-equilibrated for $10 \mathrm{~min}$ was higher significantly than when pre-equilibrated for $3 \mathrm{~min}$. Overall, the survival rate of late stage embryos of vitrification procedure used was significantly higher than early stage embryos (Table 2).

Of 33 grade 2 embryos cultured in vitro (control), $24(72.7 \%)$ developed to the blastocyst stage and were vitrified for future use. Twenty vitrified-warmed embryos that appeared morphologically normal were transferred to recipient no. 3-6 (13 embryos from 10 min equilibration group) and recipient no. 7-8 (7 embryos from $3 \mathrm{~min}$ equilibration group) resulting in

Table 1: Superovulation response of non-descript Philippine goat

\begin{tabular}{ll}
\hline Parameters & Remarks \\
\hline No. of does treated (17) & 3 did not respond; 14 responded \\
No. of ovulations (total CL's/ responding donor) & mean of 13.07 CL (183 CL) \\
Total number of structures recovered & 139 (76.0 \% recovery rate) \\
Total number of unfertilized oocytes & 3 \\
Total number of 4- to 16 - cell embryos & 31 \\
Total number of morula to blastocyst embryos & 105 (7 - Grade 3 embryos; 98 - Grade 1-2 embryos) \\
Mean number of embryos/doe & 9.7 \\
\hline
\end{tabular}


Table 2: Effect of equilibration time on the survival of vitrified goat embryos

\begin{tabular}{ccccc}
\hline Equilibration time & \multicolumn{2}{c}{ Early- stage embryos } & \multicolumn{2}{c}{ Late- stage embryos } \\
\hline$(\min )$ & vitrified & survived & vitrified & survived \\
3 & 10 & $0(0)^{\mathrm{a}}$ & 30 & $12(40.0)^{\mathrm{a}}$ \\
10 & 16 & $6(37.5)^{\mathrm{b}}$ & 36 & $25(69.4)^{\mathrm{b}}$ \\
\hline
\end{tabular}

${ }^{\mathrm{a}, \mathrm{b}}$ Values differ significantly $(\mathrm{P}<0.05)$.

Table 3: Results of transferring goat embryos

\begin{tabular}{|c|c|c|c|c|c|}
\hline Embryo & Recipient & Estrus cycle & No. of embryos & Stage of & Remarks \\
\hline Status & number & (day) & transferred & embryos & \\
\hline \multirow[t]{2}{*}{ Fresh } & $1-\mathrm{MB}$ & 5 & 3 & $3 \mathrm{CM}$ & 2 kids born alive (AN) \\
\hline & $2-\mathrm{MB}$ & 6 & 3 & $3 \mathrm{CM}$ & returned to estrus \\
\hline \multicolumn{6}{|l|}{ Vitrified- } \\
\hline \multirow[t]{6}{*}{ warmed } & 3 - Saanen & 7 & 4 & $\begin{array}{l}1-4 \text { cell, } \\
2-\mathrm{CM} ; 1-\mathrm{BL}\end{array}$ & $\begin{array}{l}4 \text { kids born alive } \\
\text { (1-Boer; } 3 \text { - AN) }\end{array}$ \\
\hline & $4-\mathrm{AN}$ & 5 & 3 & $3 \mathrm{CM}$ & returned to estrus \\
\hline & $5-\mathrm{AN}$ & 6 & 2 & $2-\mathrm{BL}$ & returned to estrus \\
\hline & $6-\mathrm{AN}$ & 6 & 4 & $2-\mathrm{BL} ; 2-\mathrm{CM}$ & 2 kids born alive $(2-\mathrm{AN})$ \\
\hline & $7-\mathrm{MB}$ & 6 & 3 & 2 - CM;1-BL & returned to estrus \\
\hline & $8-\mathrm{MB}$ & 6 & 4 & $2-\mathrm{CM} ; 2-\mathrm{BL}$ & 1 kid born alive (Boer) \\
\hline
\end{tabular}

MB - mixed breed; AN - AngloNubian; CM - compacted morula; BL - blastocyst.

$3 / 6(50.0 \%)$ pregnancies with 7 live births (35.0\%). Of 6 morula transferred fresh, 1 recipient got pregnant giving birth to 2 live kids (Table 3 ).

\section{Discussion}

Usually, the protocol for superovulation includes the administration of an intravaginal progestagen pretreatment for 11-21 day period, followed by gonadotropin treatment starting from $48-72 \mathrm{~h}$ before progestagen removal. When intravaginal progestagen treatment is carried out for a shorter period (9-11 days), a prostaglandin $\mathrm{F} 2 \alpha \quad(\mathrm{PGF} 2 \alpha)$ injection is generally administered, coinciding with the first superovulatory treatment, $24-48 \mathrm{~h}$ prior to or at progestagen withdrawal, in order to facilitate the precise timing of the onset of oestrus (Krisher et al., 1994; Kumar et al., 2003). Even when long progestagen treatment (17 days) protocols are used, it has become a practice to give an injection of PGF2 $\alpha$ (especially during breeding season), before the start of superovulatory treatment to ensure complete luteolysis and removal of any possible CL's. In contrast, past studies with Boer goats involves the use of the long synchronization program (17 days) during and outside the natural breeding season without PGF $2 \alpha$ treatment getting a mean ovulation rate of $16.5 \pm 0.8$. But when the oestrous cycle was synchronized with controlled internal drug release dispenser (CIDR, Pharmacia \& Upjohn, Auckland, New Zealand) for 7 days plus $\mathrm{PGF}_{2} \alpha(0.05$ $\mathrm{mg} /$ doe) at the time of CIDR insertion, only mean ovulation rate of $4.0 \pm 0.7$ was obtained (Lehloenya and Greyling, 2010). In this study, the super-ovulation treatment started on the $16^{\text {th }}$ day of the cycle without intravaginal progestagen treatment and $\mathrm{PGF}_{2} \alpha$ was administered at a later hour (48 and 60) after the $1^{\text {st }}$ injection of gonadotropins resulting in a mean ovulation rate of 13.07 in 14 does, while 3 did not respond to treatment. The resulting oestrous and ovulation response $(82.3 \%)$ was comparable to the rate obtained in most goat breeds so far studied (Armstrong et al., 1983; Mahmood et al., 1991; Cognie et al., 2003) including that of indigenous Feral goat in South Africa (Greyling et al., 2002). Similarly, the mean number of structures recovered per doe (9.9 including unfertilized oocytes and embryos) or 9.7 embryos per doe following flushing was comparable to that obtained in the Boer (Lehloenya et al., 2006a; 2008) when using long progestagen treatment (eg., $\mathrm{CIDR} \mathrm{PGF}_{2} \alpha / \mathrm{FSH}$ or $\mathrm{CIDR} / \mathrm{FSH}$ for 17 days) than when using CIDR for only 7 days. The low ovulation rate may be attributed to the low follicular population present in the ovary at the time of FSH stimulation, poor recruitment and development of ovarian follicles to the ovulatory stage or insufficient ovarian stimulation as in the case of shorter progestagen treatment. This occurs when a dominant follicle is present at the time of superovulation treatment - the dominant follicle being known to suppress growth and recruitment of new ovarian follicles (Driancourt, 2001).

The variability in response to superovulation in terms of different stages of embryos recovered also indicates the importance of monitoring the follicular waves when administering gonadotropins. Also, this could imply that animals used as donors are at different stages of their oestrus cycles. Other factors that warrant considerations in a superovulation procedure should include the age, weight, breed and dosage of gonadotropins to be used, especially that of hCG in trying to facilitate uniformity in ovulation. In this study, all does used as donor are within their peak of reproduction owing to the acceptable mean number of transferrable embryos recovered following flushing, though lower compared to superovulation of dairy goats, Murciano-Granadina (14.7 \pm 2.5$)$ and Jakhrana 
goats (11.8 \pm 2.9$)$ (Gonzales-Bulnes et al., 2003; Goel et al., 2005). Moreover, the FSH dosage used in the induction of superovulation in Boer was $200 \mathrm{mg} / \mathrm{doe}$ (Lehloenya and Greyling, 2010), almost ten folds higher in this study which similarly had comparable results. These observations could be ascribed to the difference on the breed used, Boer being bigger and heavier by almost 5 folds to non-descript Philippines goats. Overall, in a superovulation procedure, the ovulation time must be synchronized to facilitate better prediction of ovulation, in this case, the use of GnRH to induce ovulation would be advantageous.

Vitrification of mammalian embryos can now be performed in a variety of vitrification containers using two steps or more of CPA addition procedure. In this study, we used a simple, rapid and successful containerless method for vitrification of goat embryos. The procedure involves a brief exposure of embryos to VS1 (pre-equilibration) before transferring to VS2 for a few second, then directly plunging into $\mathrm{LN}_{2}$. The results show that post warming survival varied depending on the embryonic stages, ranging from 0 to $69.4 \%$. The post warming survival of late stage embryos was comparable to those vitrified-warmed on electron microscopy grid (Park et al., 1999), OPS (Vajta et al., 1998) or cryoloop (Lane et al., 1999b) method and resulted in successful pregnancy leading to birth of normal offspring. Apparently, the requirements for survival of early stage embryos are different from that of late stage embryos. It has been suggested that factors such as the degree of osmotic shrinkage of the cell, intracellular ice formation and osmotic swelling of the cell during the removal of cryoprotectants are contributing to the difference observed on the survival rate post-warming. In this study, it is quite difficult to specify which factor is solely responsible for the difference since the factors mentioned are closely related to the same cell characteristic. Also, the handling and manipulation of goat embryos used at room temperature could have contributed to the variations in the survival rate. These observations compliment earlier reports in vitrification experiments (Scheffen et al., 1986) and in embryos frozen rapidly (Massip et al., 1984).

Overall, the pregnancies and birth of healthy kids after transfer of vitrified-warmed embryos indicate that the container-less minimum drop size method of vitrification utilized can be used in the storage of goat embryos. That, together with the superovulation protocol used, production and collection of embryos in large number affords opportunities in enhancing the reproductive efficiency of goat and perhaps other farm animals and/or rare endangered species.

\section{References}

Armstrong DT, Pfitzner P, Warnes GM, Ralph MM, Seamark RF (1983) Endocrine responses of goats after induction of superovulation with PMSG and FSH. J Reprod Fertil 67:395-401.

Bilton RJ, Moore NW (1976) In vitro culture, storage and transfer of goat embryos. Aust J Biol Sci 29: 125129.

Cognie Y, Baril G, Poulin N, Mermillod P (2003) Current status of embryo technologies in sheep and goat. Theriogenology 59:171-188.

Driancourt MA (2001) Regulation of ovarian follicular dynamics in farm animals. Implications for manipulation of reproduction. Theriogenology 55: 1211-1239.

Goel AK, Agrawal KP (2005) Ovulatory response and embryo yield in jakhrana goats following treatments with PMSG and FSH. Trop Anim Health Prods 37:549-558.

Gonzales-Bulnes A, Carrizosa JA, Delfa C, Garcia RM, Urrutia B, Cocero MJ, Moreno J, Lopez-Sebastian A (2003) Effects of ovarian follicular status on superovulatory response of dairy goats to FSH treatment. Small Rumin Res 48:9-14.

Greyling JPC, Van Der Nest M, Schwalbach MJ, Muller $T$ (2002) Superovulation and embryo transfer in South African Boer and indigenous feral goats. Small Rumin Res 43:45-51.

Guignot F, Bouttier A, Baril G, Salvetti P, Pignon P, Beckers JF, Touze JL, Traldi AS, Cognie Y, Mermillod P (2006) Improved vitrification method allowing direct transfer of goat embryos, Theriogenology 66(4):1004-1011.

Hsu T, Yamakawa H, Yamano J, Ogawa S (1986) Survival and transfer test of mouse early embryos after vitrification. Jap J Anim Reprod 32:106-109.

Kasai M, Komi JH, Takakamo A, Tsudera H, Sakurai T, Machida T (1990) A simple method for mouse embryo cryopreservation in a low toxicity vitrification solution. J Reprod Fertil 89:91-97.

Kasai M, Hamaguchi Y, Zhu SE, Miyake T, Sakurai T, Machida T (1992) High survival of rabbit morulae after vitrification in an ethylene glycol-based solution by a simple method. Biol Reprod 46:1042-1046.

Kim DH, Park HS, Kim SW, Hwang IS, Yang BC, Im GS, Chung HJ, Seong HW, Moon SJ, Yang BS (2007) Vitrification of immature bovine oocytes by the microdrop method. J Reprod Fertil 53: 843-851.

Kim YM, Uhm SJ, Gupta MK, Yang JS, Lim JG, Das ZC, Heo YT, Chung HJ, Kong IK, Kim NH, Lee HT, Ko DH (2012) Successful vitrification of bovine blastocysts on paper container. Theriogenology 78: 1085-1093.

Krisher RL, Gwazdauskas FC, Page RL, Rusell CG, Canseco RS, Sparks AT, Velander WH, Johnson JL, Pearson RE (1994) Ovulation rate, zygote recovery and follicular populations in FSHsuperovulated goats treated with PGF2 $\alpha$ and/or GnRH. Theriogenology 41: 491-498. 
Kuwayama M, Kato O (2000). All-round vitrification method for human oocytes and embryos. J Assist Rep Genet 17: 477.

Lane M, Bavister BD, Lyons EA, Forest KT (1999a). Container-less vitrification of mammalian oocytes and embryos. Nat Biotechnol 17: 1234-1236.

Lane M, Schoolcraft WB, Gardner DK (1999b). Vitrification of mouse and human blastocyst using a novel cryoloop container-less technique. Fertil Steril 72: $1073-1078$.

Le Gal F, Baril G, Vallet JC, Leboeuf B (1993) In vivo and in vitro survival of goat frozen embryos with ethylene glycol or glycerol. Theriogenology 40: 771-779.

Lehloenya KC, Greyling JPC, Schwalbach LMJ, Grobler S (2006) Superovulatory response in Boer goats pretreated with a GnRH-agonist during the natural breeding season. South Afr J Anim Sci 36: 30-33.

Lehloenya KC, Greyling JPC, Grobler S (2008) Effect of season on the superovulatory response in Boer goats does. Small Rumin Res 78: 74-79.

Lehloenya KC, Greyling JPC (2010) The ovarian response and embryo recovery rate in Boer goat following different superovulation protocols, during breeding season. Small Rumin Res 88: 38-43.

Lindner GM, Wright RW (1983) Bovine embryo morphology and evaluation. Theriogenology 20: 407416.

Mahmood S, Koul GL, Biswas JC (1991) Comparative efficacy of FSH-P and PMSG on superovulation in Pashmina goats. Theriogenology 35:1191-1196.

Martino A, Songsasen N, Leibo LP (1996) Development into blastocyst of bovine oocytes cryopreserved by ultra-rapid cooling. Biol Reprod 54: 1059-1069.

Massip A, Van Der Zwalmen P, Leroy F (1984) Effect of stage of development on survival of mouse embryos frozen-thawed rapidly. Cryobiology 21: 574-577.

Matsumoto T, Ishiwata M, Yamanoi J, Yamakawa H, Kondo Y, Kawate S, Ogawa S (1987) Effect of sucrose dilution on survival of mouse early embryos after vitrification. Jap J Anim Reprod 33: 200-205.

Miyake T, Kasai M, Zhu SE, Sakurai T, Machida T (1993) Vitrification of mouse oocytes and embryos at various stages of development in an ethylene glycolbased solution by a simple method. Theriogenology 40:121-134.

Nuti LC, Minhas BS, Baker WC, Capehart JS, Marrack P (1987) Superovulation and recovery of zygotes from Nubian and Alpine dairy goats. Theriogenology 28:481-488.

Park SP, Kim EY, Kim DI, Park NH, Won YS, Yoon SH (1999) Efficient and successful vitrification of bovine blastocyst using electron microscope grids. Hum Reprod 14:2838-2843.

Rall WF, Fahy GM (1985) Ice-free cryopreservation of mouse embryos at $-196^{\circ} \mathrm{C}$ by vitrification. Nature 313: 573-575.

Rodriguez-Dorta N, Cognie Y, Gonzales F, Poulin N, Guignot F, Touze JL, Baril G, Cabrera F, Alamo D, Batista M, Gracia A, Mermillod P (2007) Effect of coculture on oviduct epithelial cells on viability after transfer of vitrified in vitro produced goat embryos. Theriogenology 68: 908-913.

Scheffen B, Van Der Zwalmen P, Massip A (1986) A simple and efficient procedure for preservation of mouse embryos by vitrification. Cryo-Letters 7: 260269.

Kumar SP, Saravanan D, Rajasundaran RC, Selvaraju M, Kathiresan D (2003) Serum estradiol and progesterone profiles and their relationship with superovulatory responses in Tellicherry goats treated with eCG and FSH. Small Rumin Res 49: 69-77.

Tominaga K, Hamada Y (2001). Gel-loading tip as container for vitrification of in vitro produced bovine embryos. J Reprod Dev 47: 267-273.

Vajta G, Holm P, Kuwayama M, Booth PJ, Jacobsen H, Greve T (1998) Open pulled straw vitrification: a new way to reduce cryoinjuries of bovine ova and embryos. Mol Reprod Dev 51: 53-58.

Yushiati, Holtz W (1990). Successful transfer of vitrified goat embryos. Theriogenology 34: 629-632.

Zhu SE, Kasai M, Otoge H, Sakurai T, Machida T (1993) Cryopreservation of expanded mouse blastocysts by vitrification in ethylene glycol - based solutions. J Reprod Fertilp 98: 139-145. 